\title{
Review of Researches on Talent Cultivation Models and Approaches under the Background of Guangdong-hong kong-macao Greater Bay Area
}

\author{
Jinbo Bai ${ }^{1, \mathrm{a}}$ and Hongbo $\mathrm{Li}^{2, \mathrm{~b},{ }^{*}}$ \\ ${ }^{1}$ Economics \& Management College, Zhaoqing University, Zhaoqing, China \\ ${ }^{2}$ School of Computer Science and Software, Zhaoqing University, Zhaoqing, China \\ ahljbjb@126.com, bislhb@126.com \\ ${ }^{*}$ Corresponding author \\ Keywords: Guangdong-hong kong-macao greater bay area, Talent cultivation, Models,
} Approaches.

\begin{abstract}
The outline of the development plan for the guangdong-hong kong-macao greater bay area marks that the construction and development of the greater bay area has become a national strategy, which means that the policy, capital and manpower of the greater bay area will change dramatically. Along with these changes, the modes and approaches of talent training or cultivating in finance, law, e-commerce, innovation and entrepreneurship and business English are particularly outstanding and urgent. On the basis of summarizing some research achievements, this paper summarizes the above five types of talent training models and approaches in talent training, which can be used as reference for researchers.
\end{abstract}

\section{Introduction}

In 2017, the development plan for the guangdong-hong kong-macao greater bay area turned the construction and development of the area into a national strategy. The guangdong-hong kong-macao greater bay area is the region with the best and fastest economic development in China and occupies a pivotal position. With the "One Belt And One Road" strategy put forward, guangdong, Hong Kong and Macao greater bay area as one of the starting points of the maritime silk road, is also a key construction area. The greater bay area has become a national strategy, which means huge changes in policy, capital and manpower ${ }^{[1]}$.

The outline of the development plan for the guangdong-hong kong-macao greater bay area issued in early 2019 clearly states that the construction of the guangdong-hong kong-macao greater bay area has a very important strategic position in China's future development. The guangdong-hong kong-macao greater bay area will not only be built into a vibrant city cluster, but will also gradually grow into an international scientific and technological innovation center with global influence and become an important support for the construction of "One Belt And One Road". The guangdong-hong kong-macao greater bay area will be a model area for in-depth cooperation between the mainland and Hong Kong and Macao. The fundamental goal of the construction of the guangdong-hong kong-macao greater bay area is to realize the grand and long-term economic effect of the "bay area economy" and promote the leapfrog development of the country's innovative scientific and technological forces and economic strength ${ }^{[2]}$.

With these sound basic plans and plans, and the further upgrading of infrastructure, the guangdong-hong kong-macao greater bay area has the realistic foundation and potential to develop into a world-class urban agglomeration, and in the future, it can rival the world-class greater bay areas such as the New York bay area, the Tokyo bay area and the San Francisco bay area ${ }^{[1]}$. As the main body of scientific and technological innovation, high-quality talents must be the key to realize the grand goal of the guangdong-hong kong-macao greater bay area. The development of the guangdong-hong kong-macao greater bay area is inseparable from talents from all walks of life, and these talents need to adapt to such changes quickly ${ }^{[2]}$. Therefore, the new situation requires the personnel training mode and the way must make the corresponding adjustment, creatively introduces 
the new idea, the new method carries on all kinds of personnel training to meet the future challenges and requirements.

\section{All kinds of talent training modes and approaches}

The construction of the guangdong-hong kong-macao greater bay area needs the support of multiple professionals. This paper will introduce the research results of talent training modes and approaches from the perspective of finance, law, e-commerce, innovation and entrepreneurship and business English, which are in short supply at present.

\subsection{Financial talent training}

On February 18, 2019, the CPC Central Committee and the State Council issued the outline of the development plan for the guangdong-hong kong-macao greater bay area. The outline Outlines the vision of building an international financial hub, vigorously developing characteristic financial industries, orderly promoting financial market connectivity, and building a platform for cooperation and development between guangdong, Hong Kong and Macao. Finance is the key of the development of the guangdong-hong kong-macao greater bay area. With the continuous improvement and development of the financial integration of the greater bay area, the connectivity of the financial industry in the greater bay area will generate more demands for high-quality financial talents, and cultivate high-quality financial talents in line with the needs of the financial industry in the greater bay area ${ }^{[3]}$. According to [3], under the background of the guangdong-hong kong-macao greater bay area, the following four types of financial talents are mainly needed: compound, international, technological and green, and cultivating these talents is mainly realized through the following approaches.

$\checkmark$ Adjust the curriculum according to the needs of the greater bay area;

$\checkmark$ Strengthen the construction of double-qualified teaching staff in finance;

$\checkmark$ Strengthen students' green skills training;

$\checkmark$ Strengthen the cultivation of students' international vision;

$\checkmark$ Promote coordinated development of education.

\subsection{Legal talent training}

Some researchers believe that there are some bottlenecks in the cross-border legal talent training model in the bay area, such as the separation of the three legal systems under "one country, two systems", the complexity of language environment increasing the cost of fusion, the relative shortage of teachers of cross-border law, the small number of law master or doctor programs and the smaller number of law doctoral programs, and the entry thresholds of legal service industry are inconsistent ${ }^{[4]}$. These researchers also maintain that the cultivation of legal talents can refer to the following models and approaches.

$\checkmark$ The training is mainly realized through the establishment of cross-border legal research direction or second-level law discipline, the joint training of universities or schools in the greater bay area, and the expansion of the teaching staff of cross-border legal teaching and research.

$\checkmark$ Establish social organizations for cross-border legal talent training in the greater bay area, such as the cross-border legal talent training foundation and the cross-border legal talent training seminar in the greater bay area.

$\checkmark \quad$ Establish a cross-border legal career docking mechanism between guangdong, Hong Kong and Macao.

\subsection{E-commerce talent training}

It is foreseeable that with the development and construction of the guangdong-hong kong-macao greater bay area, the demand for e-commerce talents will continue to grow. However, even in the current, our e-commerce talent is also relatively scarce. In order to cope with this problem, some researchers put forward the following talent training approaches ${ }^{[5]}$. 
$\checkmark$ Relying on the professional group to create innovative technology e-commerce talents;

$\checkmark$ Reconstructing the curriculum system of e-commerce major;

$\checkmark$ Giving full play to the role of "integrating competition and education" in cultivating innovative talents in e-commerce science and technology;

$\checkmark$ Cultivating innovative e-commerce talents in technology through school-enterprise cooperation and industry-education integration.

$\checkmark$ Cultivating innovative e-commerce talents in sciencethrough school-enterprise cooperation and industry-education integration.

\subsection{Innovative and entrepreneurial talent training}

The development of the guangdong-hong kong-macao greater bay area is inseparable from innovative and innovative industrial talents. Therefore, the outline of the development plan for the guangdong-hong kong-macao greater bay area emphasizes to actively promote the construction of innovation and entrepreneurship platform, improve the innovation and entrepreneurship ecology, and provide more opportunities and better conditions for innovation and entrepreneurship of young people in the greater bay area. Some researchers believe that there are still some significant problems in the process of cultivating innovative and entrepreneurial talents in guangdong universities, such as the need to strengthen the full-time teaching staff, the lack of innovation in educational mode, the lack of practical approaches for students, and the weak awareness of innovation and entrepreneurship of students ${ }^{[6]}$. After our induction, innovation and entrepreneurship talent training mainly through the following ways ${ }^{[2,6-13]}$.

$\checkmark$ Establish a correct concept of innovation and entrepreneurship education;

$\checkmark$ Increasing the construction of teaching staff;

$\checkmark$ Establish innovative talent training mode;

$\checkmark$ Strengthening openness and cooperation;

$\checkmark$ Adhering to the undergraduate-oriented, building a first-class innovative talent training system;

$\checkmark \quad$ Focusing on the development of emerging industries in the guangdong-hong kong-macao greater bay area and promoting the development of new engineering projects;

$\checkmark$ Promoting reform of the scientific research and innovation system and mechanisms, and enhancing the scientific research and innovation capabilities of teachers.

$\checkmark$ Being highly compatible with the important nodes of the guangdong-hong kong-macao greater bay area, and creating an innovative ecological community with levels and gradients;

$\checkmark$ Cultivating and attracting innovative talents;

$\checkmark$ Focusing on cultivating high-end talents;

$\checkmark$ Cultivating talents with the mode of "study + work";

$\checkmark$ Promoting the integration of guangdong, Hong Kong and Macao in training innovative talents;

$\checkmark$ Improving policies and regulations governing scientific research;

$\checkmark$ Improving the evaluation system for innovative talents;

$\checkmark$ Creating a good environment for innovation.

\subsection{Business English talent training}

To build a world-class bay area, improve international competitiveness, and drive and deepen exchanges and cooperation between countries along the "One Belt And One Road" strategy, we need a large number of high-quality compound business English talents who are proficient in English, business, communication and culture. Business English ability has become an indispensable core competitiveness of national development. However, there is a serious shortage in the supply of high-quality skilled business English majors. The cultivation of business English majors in many colleges and universities has the disadvantages of simplification, the lack of industrialized talents, the lack of in-depth integration of production and education, and the structure, quality and level of the talent cultivation mode and industrial demand ${ }^{[14]}$. 
In [14] researchers believe that the current business English professional talent training mainly exist in-conformity between talent training target and industry requirements, curriculum lacking of innovation, curriculum system needing to be perfect, single training methods, training condition being relatively backward, loosely regulated teaching implementation process, lacking of targeted research problems. In order to overcome the above shortcomings, they advocate that the main ways to train business English majors are as follows.

$\checkmark$ Professional setting docking industry demands, and achieving the real integration of production and education;

$\checkmark$ Adjusting the professional curriculum system, and introducing the real projects of enterprises into the classroom;

$\checkmark$ Introducing entrepreneurial space, and cultivating students' practical ability and innovation ability;

$\checkmark \quad$ Hiring enterprise experts, and building the teaching team that combines special and part-time jobs.

\section{Summary}

The construction and development of the guangdong-hong kong-macao greater bay area needs all kinds of talents. This paper mainly discusses the existing problems in the training of talents in finance, law, e-commerce, innovation and entrepreneurship, and business English and the training modes or approaches under the new situation. In the future, we will take talent training as the research objective to further track, explore and study other urgently needed professional talent training models and approaches.

\section{Acknowledgement}

This research was supported by the Research Project of 2016 Practical Teaching Reform of Zhaoqing University (No. sjjx201601), the Research Project of Education Development Research Institute of Zhaoqing City (No. ZQJYY2016043, ZQJYY2017002).

\section{References}

[1] C. Xiang, Analysis on the development opportunities of small and medium-sized enterprises' cross-border e-commerce under the background of guangdong, hong kong and macao dawan area, Journal of Hubei Open Vocational College, vol.32, pp. 111-113, 2019.

[2] Y. Chen, Enlightenment of the innovative and entrepreneurial talent cultivation model of universities in the San Francisco bay area to the talent cultivation of universities in the guangdong-hong kong-macao greater bay area. Journal of Innovation and Entrepreneurship Education, vol.10, pp. 113-116, 2019.

[3] Y. Gao, Exploration of higher vocational financial talents training mode under the background of guangdong-hong kong-macao greater bay area, Journal of Marketing Management Review, vol.10, pp. 208-209, 2019.

[4] L. Liang, Z. Feng, Research on the training model of cross-border legal talents in the guangdong-hong kong-macao greater bay area, Lingnan Journal, pp. 49-55, 124, 2019.

[5] A. Huang, Exploration on the training mode of e-commerce innovative talents in shantou vocational colleges under the radiation of guangdong-hong kong-macao greater bay area, Journal of Economic \& Trade Update, pp. 85-86, 2019.

[6] C. Yuan, and L. Han, Cultivation of innovative and entrepreneurial talents in guangdong universities under the background of guangdong-hong kong-macao greater bay area, Journal of Education Modernization, vol.8, pp. 68-69, 2019. 
[7] X. Zhang, A study o the cultivation of innovative talents in the construction process of guangdong-hongkong-macao greater bay area, Research in Higher Education of Engineering, pp. 99-102, 2019.

[8] Z. Li, Drawing lessons from the experience of the UK in cultivating innovative talents, making the guangdong-hong kong-macao greater bay area to become a highland for innovative talents, Journal of Guangdong Economy, pp. 52-55, 2019.

[9] Z. Li, F. Li, L. Xu, and Z. Huang, Analysis on the current situation of business talents training mode in universities in guangdong-hong kong-macao greater bay area, Journal of China Education Technology \& Equipment, pp. 72-74, 2018.

[10]Y. Zheng, Research on logistics talent training under the background of guangdong-hong kong-macao greater bay area, Journal of Think Tank Era, pp. 215-218, 2019.

[11]Z. Zhang, Analysis on the influence of guangdong-hong kong-macao greater bay area on the training of electrical engineering and automation professionals in local colleges and universities, Journal of Electronics World, 67, 69, 2019.

[12]W. Wang, J. Nie, Study on talent training in secondary vocational schools in guangdong-hong kong-macao greater bay area, Journal of Hebei Vocational Education, vol.2, pp. 16-19, 2018.

[13] S. Liu, Based on the international science and technology innovation center construction goal an analysis on the cultivation of science and technology innovative talents in universities in guangdong-hong kong-macao greater bay area, Journal of Guangdong Economy, pp. 38-41, 2018.

[14]C. Wang, An analysis on the cultivation system for business English talents based on the integration of production and education in the great bay area of guangdong, hongkong and macao, Journal of Heihe University, vol.10, pp. 97-98, 133, 2019. 